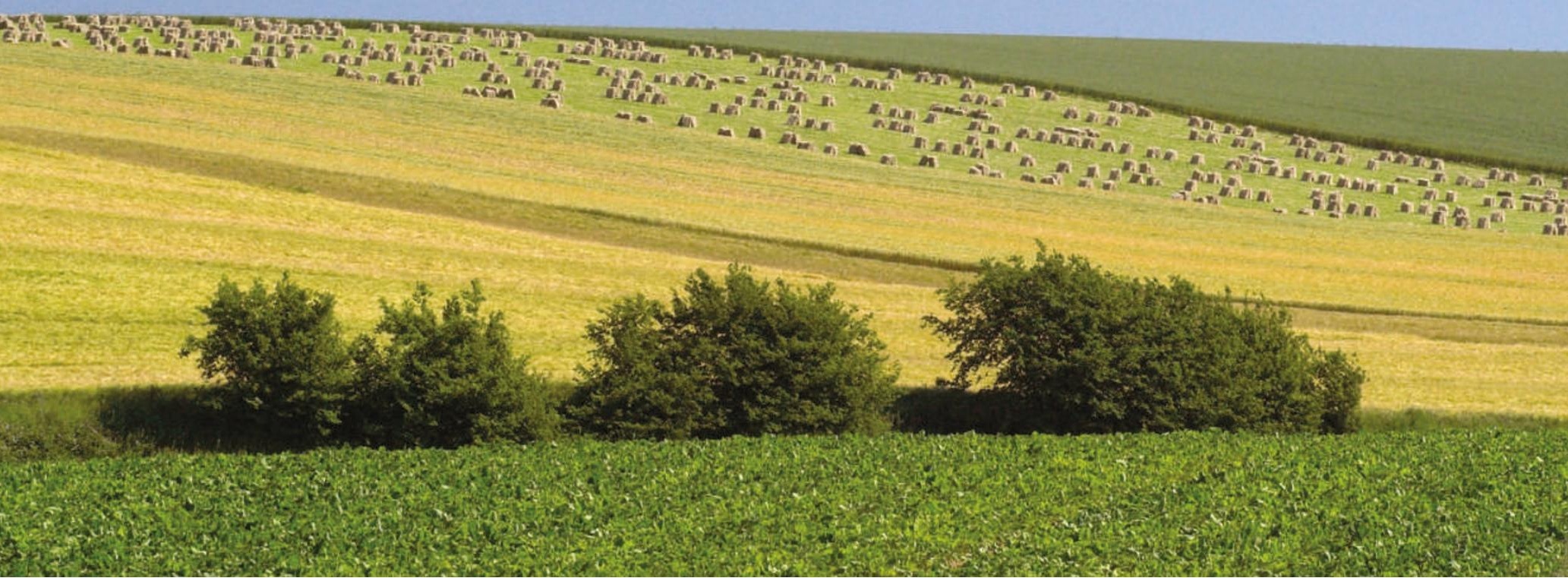

\title{
How green was my subsidy?
}

\section{Europe pumps large quantities of cash into schemes that encourage less-intensive farming. But, finds John Whitfield, some researchers are not sure what benefits they deliver.}

I 's five-and-a-half hours on the train from London to Wageningen in the Netherlands. Through Kent and the Pas de Calais, the view is of rolling arable fields; north of Brussels, it changes to a flat checkerboard of pastures, edged by ditches and dotted with old windmills and modern wind turbines. These are some of the most intensively farmed landscapes on Earth, from which plants and animals unable to earn their agricultural keep have been excluded over many years.

In the time it takes to make this journey, about $€ 2$ million (US\$2.4 million) of public money will be spent, Europe-wide, on subsidies aimed at reversing the centuries-long trend towards the highest possible efficiency in farming. Together, governments and the European Union (EU) spend roughly $€ 3.5$ billion a year on schemes aimed at encouraging less-intensive farming in order to see gains in biodiversity, landscape preservation, and water and soil quality. These schemes cover a quarter of the farmland in the 15 countries that made up the EU before enlargement - an area about the size of Germany. But their continuation is not guaranteed. The latest EU budget deal could see funding for such 'agrienvironment' schemes in these countries fall by a fifth compared with 2006 .

As well as being a daunting spending commitment, Europe's agri-environment schemes also represent one of the world's biggest ecological experiments - or they would do, had anyone bothered to formulate hypotheses or collect data. Unfortunately, from this point of view, most of Europe's agri-environment schemes have very vague goals, such as to "prevent damage to the environment" or "provide wildlife habitats". Specific targets are not set; progress is rarely monitored; the baselines from which they start are not defined. The good that they do is thus hard to measure, which in some eyes makes the schemes hard to justify. As the European Court of Auditors wrote in a critical report ${ }^{1}$ on the subject last year, "If a measure cannot be adequately checked, it should not be the subject of public payment."

\section{Going Dutch}

At the end of last month, 75 researchers, as well as conservationists and officials from Spain, Estonia and most places in between, met in Wageningen to discuss measurements of the schemes. They looked at the largest international study of agri-environment strategies so far, and talked more generally about whether such schemes work, how to tell if they do, why some are successful, and how the rest could be improved. There is definitely a lot of room for such improvement. If judged in terms of biodiversity, research suggests that almost half the schemes have no effect. A handful have an effect opposite to that intended.

The meeting was convened by ecologist David Kleijn and his colleagues at Wageningen

"It was rather depressing, wading through report after report that showed minimal benefits." - William Sutherland
University, who have pursued the subject with vigour. In 2001, in one of the first scientific audits of an agri-environment scheme, they showed that a Dutch project intended to help ground-nesting meadow birds by delaying the mowing of fields was having no effect - birds actually seemed to prefer intensively farmed fields ${ }^{2}$. The paper caused a storm. The Dutch agriculture ministry, which did not take kindly to being told it was wasting its money, summoned the researchers to explain themselves. "They really didn't like it," recalls Frank Berendse, one of the team. "I was quite amazed by the impact," adds Kleijn.

Sue Armstrong-Brown, head of agricultural policy at Britain's Royal Society for the Protection of Birds, thinks that the Wageningen research contributed to the current cuts in agri-environment spending: "You can trace a lot back to the 2001 Kleijn paper, and the debate around it - that work caused a lot of concern among policy-makers."

Kleijn went on to win EU funding for an evaluation of agri-environment schemes across Europe, a project called EASY. He began by publishing a meta-analysis in 2003 of the evaluations up to then, working with William Sutherland of the University of East Anglia in Norwich, UK. They unearthed 62 studies, of which three-quarters had been conducted in Britain or the Netherlands; a third of the delegates at the Wageningen meeting were from Britain, reflecting the higher profile of nature conservation in the north of the continent relative to the south. Many studies were rejected owing to their poor design; of the rest, $54 \%$ showed some positive effect of schemes 
on biodiversity, $6 \%$ showed a negative effect, and the rest no effect ${ }^{3}$. "It was rather depressing, wading through report after report that showed minimal benefits," says Sutherland.

That same year, Kleijn and an international team of researchers began a study of schemes in the Netherlands, Spain, Germany, Britain and Switzerland, the results of which were unveiled at January's meeting in Wageningen. This team chose pairs of nearby fields, in which one was part of a scheme and the other was not. They then surveyed the fields for five groups of creature: plants, bees, grasshoppers and crickets, spiders and birds. Out of 25 categories (five species groups in five countries), 12 showed a positive response to agri-environment schemes ${ }^{4}$.

Plants showed the most widespread benefits, with higher diversity on scheme fields in every country except the Netherlands. Bees benefited in Germany and Switzerland, grasshoppers and crickets in Britain, and spiders in Spain. In cases where the biodiversity went up, nearly all the beneficiaries were common species; only one scheme - a Spanish programme aimed at making arable fields bird-friendly by leaving winter stubble showed a positive effect on endangered species, one of which was the thekla lark (Galerida theklae). "One could argue that this lack of benefits is the most important result, because endangered species are the ones that suffer most from the intensification of agriculture," says Kleijn.

\section{Green sleeves}

His interpretation was not popular with everyone at the Wageningen meeting. British conservationists, for example, questioned the EASY team's decision to study a British scheme that pays farmers to leave strips of grass at the edges of their arable fields, saying that it was never designed to protect rare species. "It would be a bit nuts to criticize a scheme for not delivering something it wasn't designed to do," says Juliet Vickery, head of terrestrial ecology at the British Trust for Ornithology in Norfolk.

Britain's Environmental Stewardship programme of EU-approved agri-environment schemes has a small upper tier of focused, complex schemes aimed at preserving habitat for particular species, and a far broader lower

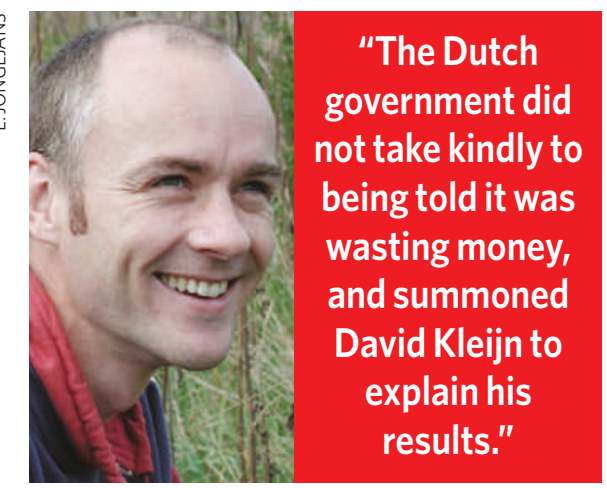

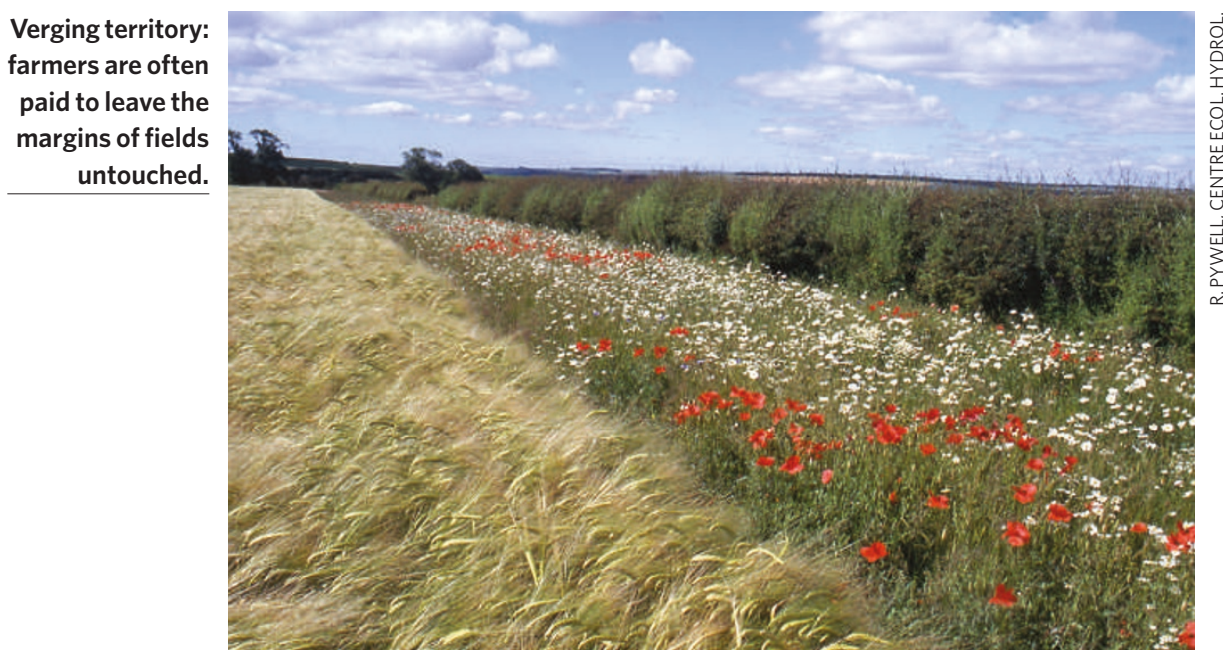

tier of things such as grassy verges, which UK conservationists expect nearly all farmers to adopt. The programme has a strong research base, with monitoring planned for 2,000 sites. "It's the best model for these schemes in the world," says Armstrong-Brown.

"There's a tremendous amount of expertise in Britain," agrees John Finn, an ecologist with Teagasc, the Irish Agriculture and Food Development Authority, "but it isn't yet being shared effectively with other countries."

The model for the upper tier of these efforts is the campaign to improve the lot of the cirl bunting (Emberiza cirlus). This English farmland bird was once widespread, but by the 1980 s it had been restricted to a small part of the southwest - although it was still common in other countries. A sustained conservation effort has paid farmers to leave stubble for winter food and to preserve grassland as a source of summer insects. Together with intensive support from the Royal Society for the Protection of Birds, this has seen the population expand sixfold in less than two decades ${ }^{5}$.

\section{To cap it all}

Kleijn accepts that intensive conservation efforts can work, but by the end of the Wageningen conference he still feared that, without focus, few schemes would achieve tangible goals. Others, however, left the meeting worried that such an emphasis on measurable results could be counterproductive. "The EASY studies are very sound, but the takehome message tends to overstate the case," says Simon Mortimer of the University of Reading, UK. "It could potentially be quite damaging to a policy that has had benefits." Just because the benefits so far have been small, he adds, does not mean the schemes aren't working.

And the failures can be understood by analysing what farmers do, and how they respond to incentives, says Jørgen Primdahl, an environmental scientist at the Royal Veterinary and Agricultural University in Frederiksberg, Denmark. Kleijn's study would have been stronger had it done this, Primdahl maintains. "Just looking at the outcomes of schemes, without any reference to agricultural practices, is not very helpful," he says. "If you have good models, you can explain why a scheme doesn't work."

In the long term, the schemes may fare well despite a lack of clear data on their results. The public is more likely to approve of paying farmers to manage the landscape than to produce food surpluses, says Hans-Jörg Lutzeyer of the European Commission, one of only two commission officials to make it to Wageningen. While centralized EU funding for agrienvironment schemes is being cut, member states have increased their freedom to switch money into environmental measures from other farm subsidies. World Trade Organization rules, which prohibit subsidies for food production but allow them for the environment, add to the attractions of agri-environment projects for Europe.

Such schemes may not be the best way to promote the preservation of endangered species. Sutherland, for one, argues that Europe might do better to allow some areas to revert to a state close to wilderness while others are intensively farmed, and then to manage the whole system so as to maximize leisure, flood protection, and water quality. He says biodiversity benefits would accrue even if not particularly targeted ${ }^{6}$. But Europeans like farmland landscapes, and will probably continue to try and convince themselves that there are practical ways to keep areas that are rich in wildlife and pleasing to the eye, which also produce cheap food and don't pollute streams and rivers.

"It's worth remembering how weird Western European conservation is," Sutherland says. "If you tell American, Asian or African conservationists that we farm in national parks, they look at you in disbelief." John Whitfield is a freelance writer based in London.

\footnotetext{
European Court of Auditors Official J. Eur. Union Sp. Rep. No 3/2005 (2005).

2. Kleijn, D., Berendse, F., Smit, R. \& Gilissen, N. Nature 413, 723-725 (2001).

3. Klein, D. \& Sutherland, W. J. J. Appl. Ecol. 40, 947-969 (2003)

4. Kleijn, D. et al. Ecol. Lett. doi:10.1111/j.1461-0248.2005. 00869.x (2006)

5. Peach, W. J., Lovett, L. J., Wotton, S. R. \& Jeffs, C. Biol. Conserv. 101, 361-373 (2001).

6. Sutherland, W. J. Ibis 146, 230-238 (2004).
} 